\title{
Prayer and Wisdom on the Board of on Environmental Cleaning Warnings: Functions and Meaning
}

\author{
Ira Mayasari* \\ Universitas Indraprasta PGRI \\ *) Correspondences author: Jl. Raya Tengah No. 80, Kel. Gedong, Kec. Pasar Rebo, Jakarta Timur 13760, Indonesia; \\ e-mail: bunazmina@gmail.com
}

\begin{abstract}
The purpose of this study was to determine the function of language and affective meaning on environmental hygiene warning boards. This research is a qualitative descriptive study, namely by analyzing writing data on environmental hygiene warning boards. The object of this research is written data on the father of environmental hygiene warnings taken from the internet. The conclusions from the results of the study are that there are three language functions, namely informational, expressive, and directive functions. From 42 data, there are 13 informational functions, 14 expressive functions, and 15 directive functions. Based on the meaning, 13 positive affective meanings and 28 negative affective meanings were found.
\end{abstract}

Key Words: warning board, semantics, affective meaning

\section{Article History: Received: 27/10/2018; Revised: 24/11/2018; Accepted: 14/12/2018; Published: 25/12/2018}

How to Cite (MLA 7th): Mayasari, Ira. "Prayer and Wisdom on the Board of on Environmental Cleaning Warnings: Functions and Meaning" Hortatori Jurnal Pendidikan Bahasa dan Sastra Indonesia 2.2 (2018): 92-99. Print/Online. Copyrights Holder: Mayasari, Ira. First Publication: Hortatori Jurnal Pendidikan Bahasa dan Sastra Indonesia (2018).

This work is licensed under a Creative Commons Attribution-ShareAlike 4.0 International License.

\section{Pendahuluan}

Bahasa digunakan untuk menyampaikan pesan, baik secara langsung maupun tidak langsung. Bahasa yang digunakan bisa secara lisan maupun tertulis. Bahasa tulis dan lisan memiliki kesamaan fungsi, yaitu untuk menyampaikan pesan dari penutur kepada lawan tutur. Bahasa lisan disampaikan langsung, dari penutur kepada lawan tutur, baik langsung, maupun melalui telepon. Berbeda dengan bahasa lisan, bahasa tulis tidak langsung membutuhkan lawan tutur.

Objek dalam penelitian ini adalah bahasa tulis, yaitu papan peringatan kebersihan lingkungan. Pada papan peringatan yang dipasang di tempat-tempat umum, ada pesan yang disampaikan kepada pembacanya. Tujuan memasang papan peringatan adalah untuk memberi petunjuk kepada siapa saja yang berada di lokasi tersebut. Dengan demikian, sebaiknya tulisan dalam papan peringatan singkat dan jelas sehingga tidak menimbulkan makna ambigu. Namun, ada hal yang menarik dari tulisan pada papan peringatan. Begitu kreatifnya sehingga tulisan pada papan peringatan memiliki berbagai macam fungsi dan makna.

Pada dasarnya, papan peringatan kebersihan lingkungan berfungsi agar siapa pun yang melintas di lokasi tersebut dapat menjaga kebersihan. Inti dari peringatan tersebut adalah untuk membuang sampah pada tempatnya. Biasanya ditulis dengan "Dilarang membuang sampah sembarangan" ataupun "Buanglah sampah pada tempatnya". Menariknya, zaman sekarang ini peringatan-peringatan pada papan ditulis dengan pesan yang unik. Doa dan sumpah serapah menjadi pilihan untuk menyampaikan pesan karena penulis pada papan tersebut merasa kesal dengan ketidakdisiplinan yang dilakukan warga. Doa merupakan permohonan (harapan, permintaan, pujian) kepada Tuhan, tetapi dalam papan tersebut doa yang disampaikan bersifat negatif. demikian juga dengan sumpah serapah. Sumpah serapah juga memiliki arti negatif, yaitu berbagai kata yang buruk, maki-makian disertai kutukan dan sebagainya. Keunikan tersebut terkadang membuat para pembacanya tertawa, heran, takut, bahkan kesal. Misalkan, "Ya Allah....!!!! 
Cabutlah nyawa orang yang suka buang sampah di sini", "Bila Anda ketahuan membuang sampah di sepanjang jalan ini, akan dikenakan sanksi tegas, dan diambil istrinya".

Adanya tulisan -tulisan tersebut membuat penulis tertarik untuk menganalisis fungsi dan makna dibalik tulisan pada papan peringatan untuk membuang sampah pada tempatnya.

Semantik diartikan sebagai cabang linguistik yang membahas arti atau makna (Arifin, dkk. 2015:158). Sejalan dengan pendapat tersebut, Tarigan menyatakan bahwa semantik adalah cabang linguistik yang menelaah lambang-lambang atau tanda-tanda yang menyatakan makna, hubungan makna yang satu dengan yang lain, dan pengaruhnya terhadap manusia dan masyarakat (Chaer, 2013: 5). Objek kajian semantik adalah bahasa. Dengan kata lain, makna satuan-satuan bahasa, seperti kata, frase, klausa, kalimat, dan wacana (Chaer, 2013:6). Verharr (2001: 384) membedakan semantik menjadi dua, yaitu semantik gramatikal dan semantik leksikal. Istilah semantik digunakan para ahli bahasa untuk menyebut salah satu cabang ilmu bahasa pada tataran makna atau ilmu bahsa yang mempelajari makna.

Dari segi komunikatifnya, fungsi bahasa dibedakan menjadi 5, yaitu fungsi informasional, ekspresif, direktif, fatik, estetik (Leech, 2003). Pertama fungsi informasional, brfungsi untuk memperoleh informasi, apalagi bahasa merupakan media komunikasi. Kedua, fungsi ekspresif, yaitu bahasa juga dapat dipakai untuk mengungkapkan perasaan dan sikap penuturnya. Misalkan kata-kata sumpah serapah dan kata seru. Bahasa puitis juga merupakan bentuk ekspresi emosi si penyair. Ketiga, fungsi direktif, yaitu dapat memengaruhi perilaku atau sikap orang lain. Contoh, kalimat perintah dan permohonan. Keempat, fungsi fatik untuk menjaga agar garis komunikasi tetap terbuka dan untuk terus menjaga hubungan sosial secara baik. Kelima, fungsi estetik, yaitu penggunaan bahasa dalam suatu karya, tanpa maksud yang tersembunyi.

Bolinger (dalam Aminuddin, 2011:52-53) menyebutkan bahwa makna adalah hubungan antara bahasa dengan dunia luar yang telah disepakati bersama oleh pemakai bahasa sehingga dapat saling dimengerti. Ada tiga unsur pokok yang tercakup di dalam analisis makna, yaitu (1) makna adalah hasil hubungan antara bahasa dengan dunia luar, (2) penentuan hubungan terjadi karena kesepakatan para pemakai, dan (3) perwujudan makna dapat digunakan untuk menyampaikan informasi sehingga dapat saling dimengerti. Hornby (dalam Pateda, 2001:45) mengemukakan bahwa makna ialah apa yang kita artikan atau apa yang kita maksud. Poerwadarminta (dalam Pateda, 2001:45) mengatakan makna adalah arti atau maksud. Pateda juga menggolongkan makna menjadi beberapa jenis, yaitu makna afektif, denotatif, deskriptif, ekstensi, emotif, gereflekter, gramatikal, idesional, intensi, khusus, kiasan, kognitif, kolokasi, konotatif, konseptual, konstruksi, kontekstual, leksikal, lokusi, luas, piktorial, proposisional, pusat, referensial, sempit, stilistika, tekstual, tematis, umum. Dalam penelitian ini hanya difokuskan pada satu makna, yaitu makna afektif.

Makna afektif (Inggris: affective meaning, Belanda: affective betekenis) merupakan makna yang muncul akibat reaksi pendengar atau pembaca terhadap penggunaan kata atau kalimat. Misalnya, makna kata "anjing" dalam kalimat berikut memiliki nilai emosi yang berbeda (Pateda, 2001:96). Sejalan dengan pendapat tersebut, makna afektif adalah makna sebuah kata yang mencerminkan perasaan pribadi penutur, termasuk sikapnya terhadap pendengarnya, atau sikapnya mengenai sesuatu yang dikatakannya (Leech, 2003:20). Makna afektif merupakan makna yang muncul akibat reaksi pendengar atau pembaca terhadap penggunaan kata atau kalimat. Dengan demikian, makna afektif berhubungan dengan reaksi pendengar atau pembaca dalam dimensi rasa. Dengan sendirinya makna afektif berhubungan dengan gaya bahasa. Reaksi yang ditimbulkan dapat bermakna positif dan negatif.

\section{Metode}

Jenis penelitian yang digunakan dalam penelitian ini adalah penelitian deskriptif kualitatif. Artinya penelitian ini bertujuan untuk mendeskripsikan fungsi dan makna afektif pada papan peringatan kebersihan lingkungan.

Penelitian kualitatif adalah penelitian yang bermaksud untuk memahami fenomena tentang apa yang dialami oleh subjek penelitian, misalnya perilaku, persepsi, tindakan, dan lain-lain. Laporan penelitian berupa kutipan-kutipan data untuk memberikan gambaran penyajian laporan tersebut (Moleong, 2013:11). 
Data dalam penelitian ini diambil dari sumber internet sejumlah 41 data dengan laman (https://www.google.com/search?q=tulisan+pada+papan+peringatan+dilarang+membuang+sampah).

\section{Hasil dan Diskusi}

\section{Fungsi dan Makna Afektif pada Papan Peringatan Kebersihan Lingkungan}

\section{Fungsi Informasional}

1) TAHUKAH ANDA fungsi dari TEMPAT SAMPAH? Agar anda tidak membuang sampah sembarangan.

Data (1) terdiri dari dua kalimat. Pesan pada kalimat tersebut berfungsi informasional karena pada kalimat pertama ada kalimat interogatif, kemudian dilanjutkan dengan kalimat kedua yang merupakan informasi (kalimat deklaratif). Kalimat kedua merupakan jawaban dari kalimat pertama. Informasi yang diperoleh adalah fungsi dari tempat sampah agar pembaca tidak membuang sampah di sebarang tempat.

Data (1) memiliki makna afektif negatif. penulis pada papan tersebut berasumsi bahwa kemungkinan pembaca ada yang tidak tahu fungsi dari tempat sampah sehingga diperjelas dengan jawaban setelahnya.

2) HANYA MONYET YANG BOLEH BUANG SAMPAH SEMBARANGAN.

Data (2) terdiri dari satu kalimat, yaitu kalimat deklaratif. Fungsi dari kalimat tersebut adalah memberikan informasi bahwa hanya binatang monyet yang boleh membuang sampah sembarangan.

Data (2) memiliki makna afektif negatif karena adanya kata monyet. Jadi, jika pembaca membuang sampah sembarangan, ia tergolong sebagai binatang monyet.

3) "KEBERSIHAN ADALAH SEBAGIAN DARI IMAN" JADI... ORANG BERIMAN TIDAK MUNGKIN BUANG SAMPAH SEMBARANGAN.

Data (3) terdiri dari dua kalimat. Kedua kalimat tersebut merupakan kalimat deklaratif. Informasi pertama bahwa kebersihan itu sebagian dari iman, sedangkan informasi kedua merupakan bentuk informasi lanjutan dari kalimat pertama, yaitu jika pembaca merupakan orang yang beriman, pasti tidak mungkin membuang sampah di sembarang tempat.

Data (3) memiliki makna afektif positif karena kalimat pertama memiliki informasi positif. Pada kalimat kedua bermakna, jika pembaca merupakan orang beriman pasti akan membuang sampah pada tempatnya.

4) "Bila Anda ketahuan membuang sampah di sepanjang jalan ini, akan dikenakan sanksi tegas, dan diambil istrinya"

Data (4) terdiri dari satu kalimat, yaitu kalimat deklaratif. Informasi yang terdapat pada kalimat tersebut adalah jika orang yang melintas ketahuan membuang sampah sembarangan maka akan diberikan sangsi tegas dan diambil istrinya.

Data (4) memiliki makna afektif negatif karena ada ketidaksesuaian makna antara klausa pertama dan kedua. Sanksi tegas dan dimbil istrinya merupakan bentuk emosi penulis, namun ditambah dengan sedikit lelucon agar pembaca tidak membuang sampah sembarangan.

\section{5) YA ALLAH... HANYA ORANG KAFIR SAJA YANG MEMBUANG SAMPAH DI SEPANJANG} JALAN INI.

Data (5) terdiri dari satu kalimat, yaitu kalimat deklaratif. Informasi dari kalimat tersebut adalah bahwa hanya orang kafir yang membuang sampah di sepanjang jalan lokasi tersebut.

Data (5) memiliki makna afektif negatif karena adanya kata kafir. Kata kafir bermakna menolak atau tidak percaya, atau secara singkat kafir adalah kebalikan dari percaya (beriman). Pesan tersebut dapat menimbulkan emosi pembacanya. Namun, terlihat adanya emosi juga pada penulis pada papan tersebut. Hal itu disebabkan seringnya orang yang melintas tidak membuang sampah pada tempatnya. 
6) Kata ayah, buang sampah itu harus pada tempatnya.. Kalau buang sampah sembarangan Kapan Sehatnya?

Data (6) terdiri dari dua kalimat, yaitu kalimat deklaratif dan interogatif. Fungsi dari kalimatkalimat tersebut adalah membuang sampah itu harus pada tempatnya karena kalau membuang sampah sembarangan bisa sakit.

Makna dari kalimat-kalimat tersebut adalah afektif positif. Makna dari penulis pesan dapat diterima dengan baik oleh pembaca, tanpa harus menyinggung perasaannya.

\section{7) MALU DONG BUANG SAMPAH SEMBARANGAN}

Data (7) terdiri dari satu kalimat deklaratif. Fungsi dari kalimat tersebut adalah memberikan informasi bahwa seharusnya pembaca malu jika membuang sampah sembarangan.

Makna dari kalimat tersebut adalah afektif positif. Makna tersebut dapat memengaruhi membaca sehingga pembaca menjadi tidak enak hati jika membuang sampah sembarangan. Namun, tidak menimbulkan ketersinggungan.

8) BUANG SAMPAH SEMBARANGAN DENDA Rp. 5.000,-

Data (8) merupakan kalimat deklaratif, yaitu memberikan informasi kepada pembacanya bahwa akan dikenakan denda sebesar Rp 5.000,- jika membuang sampah sembarangan.

Kalimat tersebut memiliki makna afektif positif karena hanya menyampaikan pesan kepada pembaca jika membuang sampah sembarangan akan dikenakan denda, tanpa menyinggung perasaan pembaca.

9) Buanglah sampah pada tempatnya, Alam telah menyediakan segalanya untuk kita, kitalah yang berkewajiban menjaganya.

Data (9) berfungsi memberikan informasi bahwa alam menyediakan segalanya dan harus dijaga.

Makna dari kalimat tersebut adalah makna afektif positif, yaitu adanya pesan yang disampaikan oleh penulis pada papan bahwa alam menyediakan semuanya untuk manusia, jadi harus dijaga, salah satunya dengan membuang sampah pada tempatnya.

10) LELAKI SEJATI MBUANG SAMPAH PADA TEMPATNYA

Data (10) berfungsi informasional karena memberikan informasi kepada pembaca, khususnya lelaki, yaitu jika merasa lelaki sejati berarti harus membuang sampah pada tempatnya.

Kalimat tersebut memiliki makna afektif positif, yaitu jika merasa benar-benar lelaki, akan membuang sampah pada tempatnya.

11) YANG BUANG SAMPAH DI SUNGAI/JEMBATAN KOYO AKU (gambar monyet)

Data (11) berfungsi informasional karena ada informasi yang disampaikan bahwa siapa pun yang membuang sampah di sungai atau jembatan pada lokasi tersebut seperti monyet.

Kalimat tersebut bermakna afektif negatif karena ada kata monyet. Siapa pun yang membuang sampah di lokasi tersebut disamakan dengan monyet (binatang). Makna dalam kalimat tersebut dapat membuat pembacanya tersinggung, tetapi dapat juga membuat pembaca tertawa.

12) SAMPAH ITU KOTORAN, EEK ITU KOTORAN, KALAU LO MALU BOKER SEMBARANGAN, SEHARUSNYA LO MALU BUANG SAMPAH SEMBARANGAN

Data (12) berfungsi informasional karena memberikan informasi bahwa sampah dan eek samasama kotoran, jadi seharusnya malu jika membuang samaph sembarangan.

Kalimat tersebut memiliki makna afektif positif karena ada kata eek, lo, boker. Adanya katakata tersebut memiliki nilai rasa negatif, sehingga ada kemungkinan pembaca merasa bahasa tersebut kasar. Namun, ada juga pembaca yang merasa bahwa informasi tersebut dikemas dalam bahasa yang lucu. 


\section{3) ORANG BIJAK BUANG SAMPAH PADA TEMPATNYA}

Data (13) berfungsi informasional karena memberikan informasi bahwa orang bijak itu membuang sampah pada tempatnya.

Kalimat tersebut bermakna afektif positif karena makna yang disampaikan tidak menimbulkan nilai rasa negatif. makna dari kalimat tersebut adalah bahwa orang yang selalu menggunakan akal budidaya, pandai, dan mahir akan membuang sampah pada tempatnya.

\section{Fungsi Ekspresif}

14) Yang membuang sampah disini mudah-mudahan pulangnya ketabrak mobil.

15) Dilarang membuang sampah disini. Jika masih buang disini, mudah-mudahan rezeki nya seret seumur hidup.

16) Yang buang sampah di sini semoga jadi gila.

17) YA ALLAH, YA TUHAN KAMI, CABUTLAH NYAWA ORANG YANG MEMBUANG SAMPAH DI SEPANJANG JALAN INI, AZABLAH SELURUH KELUARGANYA, PERSULITLAH SEGALA URUSANNYA, JADIKANLAH KETURUNANNYA ANAK YANG DURHAKA, MASUKKANLAH KE NERAKA JAHANAM..., AMIEENN... AL-FATEHAH...

18) BANGSAT.....!!!! BUANG SAMPAH DI JALAN INI BENJOL DIAWASI WARGA. DICATAT PLAT NO. MOTORNYA

19) YANG BUANG SAMPAH TABRAKAN!!! MAMPUS.

20) YANG MEMBUANG SAMPAH DI SINI TIDAK SELAMAT DUNIA AKHIRAT

21) PERINGATAN KERAS!!! BERANI BUANG SAMPAH, SEMBARANGAN NYAWA TARUHANNYA. DIBACOK WARGA JANGAN SALAHKAN KAMI

22) DILARANG BUANG SAMPAH DISINI NANTI TAK TEMBAK

23) DILARANG BUANG SAMPAH DISINI!!! YANG BUANG SAMPAH DISINI KAMI SUMPAHI HIDUPNYA SENGSARA, USAHA ANDA BANGKRUT, KERJAAN ANDA KACAU, SIAL SEPANJANG HIDUP AAMIIN!! SILAHKAN COBA KALAU BERANI

24) BUANG SAMPAH Nang Kene TAK DUNGAKKE KESURUPAN

25) Dilarang buang sampah disini. Kalau Anda tidak mengerti, golok akan bicara!!!

26) Bila kamu!! Berpendidikan Jangan buang sini

Data (14) sampai (26) berfungsi ekspresif karena penulis pada papan melibatkan adanya emosi yang berlebihan, yaitu doa tidak baik dan sumpah serapah.

Makna kalimat pada kesepuluh kalimat tersebut adalah afektif negatif karena ada nilai rasa negatif yang dirasakan pembacanya. Pada kalimat (14), adanya kata ketabrak menimbulkan asumsi yang tidak baik. Makna keseluruhan pada kalimat tersebut adalah siapa pun orang yang membuang sampah di lokasi tersebut didoakan agar pulangnya tertabrak mobil; data (15) bermakna, jika ada yang membuag sampah di lokasi tersebut, akan memiliki rezeki seret (sulit) seumur hidup; data (16) bermakna jika membuang sampah sembarang, orang tersebut didoakan menjadi menjadi gila; data (17) bermakna afektif negatif, yaitu berdoa dan mengeluarkan sumpah semoga nyawanya dicabut, keluarganya diazab, dan segala urusannya akan dipersulit, anaknya menjadi durhaka, dan dimasukkan ke dalam neraka jahanam oleh Allah SWT.

Pada kalimat (18) ada kata bangsat dan benjol yang ditujukan untuk orang yang membuang sampah sembarangan. Pembaca merasa bahwa bahasanya kasar karena bangsat bermakna brengngsek atau munafik; data (19) ada kata mampus yang berarti mati dan diungkapkan dengan diksi yang kasar; data (20) juga ada luapan emosi, yaitu tidak selamat dunia akhirat; data (21) ada frasa nyawa taruhannya dan dibacok warga. Pada kalimat tersebut juga disertakan beberapa tanda seru yang membuktikan bahwa penulis pada papan benar-benar emosi pada warga yang membuang sampah sembarangan; data (22) ada ancaman dengan frasa tak tembak (akan ditembak); data (23) ada kata sumpahi, sengsara, bangkrut, kacau. Kalimat tersebut terdapat kata-kata dengan diksi yang memiliki nilai rasa negatif; kalimat (24) juga ada harapan atau doa yang memiliki nilai rasa negatif, yaitu kata kesurupan (kerasukan/kemasukan setan); data (25) juga memiliki makna afektif negatif karena ada istilah ancaman, yaitu golok berbicara yang bermakna jika membuang sampah sembarangan orang tersebut bisa digolok oleh seseorang; pada kalimat (26), ada sindiran, yaitu jika Anda berpendidikan ditambahkan dengan tanda tiga tanda seru. Makna keseluruhan dari 
kalimat tersebut adalah jika pembaca termasuk orang yang berpendidikan pasti akan membuang sampah pada tempatnya. Jika tidak berarti termasuk orang yang tidak berpandidikan.

\section{7) BERI CONTOH BAIK PADA YANG LEBIH MUDA, JANGAN BUANG SAMPAH SEMBARANGAN.}

Data (27) berfungsi ekspresif karena terdapat kalimat suruhan, yaitu beri contoh baik pada yang lebih muda agar tidak membuang sampah sembarangan.

Kalimat tersebut memiliki makna afektif negatif karena ada nilai rasa negatif pada maknanya. Frasa pada yang lebih muda dapan menimbulkan asumsi bahwa yang pembacanya lebih tua.

\section{Fungsi Direktif}

28) Dilarang buang sampah disini iBu

29) Dilarang buang sampah di sitih, disini kecuali buang duit

Data (28) dan (29) berfungsi direktif karena merupakan kalimat larangan, yaitu melarang orang membuang sampah sembarangan.

Makna dari kalimat (28) adalah afektif positif. Meskipun pesan tersebut khusus untuk kaum ibu, namun disampaikan secara sopan. Kekurangannya jika pembacanya bukan seorang ibu, kemungkinan akan cuek dengan peringatan tersebut. Makna kalimat (29) adalah afektif negatif karena ada kata duit yang berarti uang. Makna keseluruhan dari kalimat tersebut adalah dilarang membuang sampah sembarangan di lokasi tersebut, tetapi diperbolehkan membuang uang. Penulis pada papan memberikan sedikit humor pada kalimat tersebut sehingga menyebabkan pembaca tertawa.

30) Ya Allah, Aku Rela Miskin 7 Turunan, Kalau Buang Sampah Di Sepanjang Jalan Ini.

31) NENG, BUANG SAMPAH DI TEMPATNYA YA, SELANJUTNYA URUSAN AA'.

Kalimat (30) dan (31) berfungsi direktif karena berupa permohonan dan permintaan.

Makna kalimat (30) afektif negatif karena adanya kata miskin. Doa atau permohonan kepada Allah bahwa penulis yang berperan sebagai pelaku rela menjadi miskin jika membuang sampah sembarangan dapat memengaruhi pembaca dan menimbulkan nilai rasa negatif. Kalimat (31) bermakna afektif positif karena tidak menimbulkan nilai rasa negatif. Sebutan Neng dan AA' juga memiliki nilai rasa positif.

32) JANGAN BUANG SAMPAH DI SINI, AWAS...! ANGKER, SUDAH BANYAK KEJADIAN LOOO...?

33) BILA ANDA TIDAK MAMPU MEMBUANG SAMPAH PADA TEMPATNYA MAKA TELAN MAKANAN/MINUMAN ANDA BESERTA BUNGKUSNYA!!!!

34) APAPUN KENDARAAN YANG ANDA NAIKI JANGAN BUANG SAMPAH KE JALAN!

35) INI SUNGAI BUKAN TEMPAT SAMPAH!!! JIKA ANDA BUKAN ORANG SEMBARANGAN, JANGAN BUANG SAMPAH SEMBARANGAN

36) Jangan Cuma MANTAN yang dibuang Sampah Juga!!

Kalimat (32) sampai (36) berfungsi direktif karena kalimat (32) dan (34) merupakan kalimat larangan, kalimat (33) dan (36) merupakan seruan, sedangkan kalimat (34) merupakan kalimat seruan dan larangan.

Makna dari kalimat (32) adalah afektif negatif. Kata awas (waspada) dan angker (ada hantunya) dapat memengaruhi pembaca sehingga menimbulkan rasa takut. Kalimat (33) memiliki makna afektif negatif karena kalimat tersebut memiliki nilai rasa negatif. makna keseluruhan kalimat tersebut adalah jika tidak bisa membuang sampah pada tempatnya, lebih baik telan bungkusnya supaya tidak mengotori lingkungan. Penulis menambahkan sisi humor, yaitu telan bungkus makanan dan minumannya. Makna pada kalimat (34) adalah afektif positif karena pesan yang disampaikan tidak menimbulkan nilai rasa negatif. makna yang disampaikan adalah, kendaraan apa pun jenisnya, tidak boleh membuang sampah sembarangan. 
Makna pada kalimat (35) adalah afektif negatif, karena ada kata sembarangan (asal-asalan) yang dapat menimbulkan nilai rasa negatif pada pembacanya. Makna dari kalimat (36) adalah afektif negatif, didukung dengan adanya kata mantan (orang yang pernah mengisi hati kemudian pergi). Kalimat tersebut mengandung unsur humor karena makna keseluruhan adalah sampah diibaratkan dengan mantan, harus sama-sama dibuang.

37) AYO BUANG SAMPAH PADA TEMPATNYA SAMPAHMU CERMINAN DIRIMU

38) PERHATIAN MOHON TIDAK MEMBUANG SAMPAH DI SALURANG KASIHAN PETANI

39) LETAKKAN SAMPAH PADA TEMPATNYA. AKSI BUANG SAMPAH pungut buang

40) MASIH PUNYA IMAN! JAGALAH KEBERSIHAN BUANG SAMPAH PADA TEMPATNYA!! \#hanya yang stupid yang gak bisa baca

41) BUANGLAH SAMPAH PADA TEMPATNYA SEBELUM ANDA DIBUANG BERSAMA TEMPATNYA!

42) YUK...BUANG sampah pada tempatnya, Siapapun aku, kamu, kita semua

Kalimat (37) sampai (42) berfungsi direktif karena merupakan kalimat permintaan. Makna dari kalimat (37) adalah afektif negatif, hal tersebut didukung dengan adanya kata sampahmu. Makna kalimat tersebut adalah mengajak pembaca untuk membuang sampah pada tempatnya karena sampah yang dimiliki diri sendiri merupakan cerminan pemiliknya. Makna kalimat (38) adalah afektif positif. Kalimat tersebut disampaikan dengan sopan, yaitu diawali dengan kata mohon. Makna kalimat tersebut adalah agar pambaca tidak membuang sampah di saluran air karena air tidak bisa mengalir. Jika air di saluran tidak mengalir, kasihan para petani, sawahnya bisa kekeringan. Makna kalimat (39) adalah afektif positif. Kalimat tersebut diawali dengan ajakan, yaitu informasi aksi membuang sampah pada tempatnya. Makna kalimat (40) adalah afektif negatif. kalimat tersebut dapat menimbulkan nilai rasa negatif, "masih punya iman!!!" ditambah tiga tanda seru. Makna kalimat (41) afektif negatif kaena menimbulkan nilai rasa negatif. makna dalamkalimat tersebut adalah ajakan untuk membeuang sampah pada tempatnya, sebelum pembaca juga dibuang bersama tempatnya. Asumsi pembaca bisa berbeda-beda, ada yang tertawa, ada juga yang tersinggung. Makna kalimat (42) adalah afektif positif karena merupakan kalimat ajakan yang disampaikan dengan sopan, tanpa memiliki nilai rasa negatif.

\section{Simpulan}

Berdasarkan hasil analisis tulisan pada papan peringatan kebersihan lingkungan, terdapat tiga fungsi bahasa, yaitu fungsi informasional, ekspresif, dan direktif. Dari 42 satu data, terdapat 13 fungsi informasional, 14 fungsi ekspresif, dan 15 fungsi direktif. Berdasarkan maknanya, ditemukan makna afektif positif sebanyak 13 dan makna afektif negatif sebanyak 28.

Inti pesan dari papan peringatan adalah ajakan untuk membuang sampah pada tempatnya dan larangan untuk membuang sampah sembarangan. Namun, adanya kekesalan dari penulis pesan menyebabkan munculnya peran emosi ketika menulis peringatan. Hal tersebut terjadi karena kurangnya kedisiplinan masyarakan untuk menjaga lingkungan dengan cara membuang sampah pada tempatnya. Dari sisi bahasa, timbulnya rasa emosi pada penulis papan reklame dapan mengadirkan suatu kreativitas, meskipun terkadang memiliki nilai rasa negatif. kreativitas tersebut dapat memberikan penilaian tersendiri bagi masyarakat, ada yang merasa pesan dari papan tulisan tersebut kurang pantas, tidak relevan, bahkan sebagai bentuk humor.

\section{Ucapan Terima Kasih}

Terima kasih kepada semua pihak yang membantu penulis dalam menyelesaikan artikel hasil riset ini sehingga bisa diterbitkan di Jurnal Hortatori. 


\section{Daftar Rujukan}

Aminuddin. Semantik Pengantar Studi Tentang Makna. Bandung: Sinar Baru Algesindo, 2011. Print. Arifin, E. Zaenal. Asas-Asas linguistik Umum. Jakarta: Pustaka Mandiri, 2015. Print.

Chaer, Abdul. Pengantar Semantik Bahasa Indonesia. Jakarta: Rineka Cipta, 2013. Print.

Leech, Goeffrey. Semantik. Yogyakarta: Pustaka Pelajar, 2003. Print.

Moleong. Metodologi . Penelitian Kualitatif. Bandung: Remaja Rosdakarya, 2013. Print.

Pateda, Mansoer. Semantik Leksikal. Jakarta: Rineka Cipta, 2001. Print.

Verhaar. Asas- Asas-asas Linguistik Umum. Yogyakarta: UGM, 2001. Print. Asas-asas Linguistik Umum. Yogyakarta: UGM. 2001. 